\title{
Effect of Thermal Annealing on the Sensitivity of Makrofol-DE Polycarbonate
}

\author{
A. Kahraman ${ }^{a, *}$, A. POFFiJn ${ }^{b}$ And G. KAYNAK ${ }^{a}$ \\ ${ }^{a}$ Physics Department, Faculty of Arts and Science, Uludag University \\ Gorukle Campus, 16059 Gorukle, Bursa, Turkey \\ ${ }^{b}$ Department of Subatomic and Radiation Physics, University of Gent, Proeftuinstr. 86, Gent B-9000, Belgium \\ Solid state nuclear track detectors have been applied in different studies including nuclear physics, particle \\ physics, archaeology etc. Makrofol, a particular group of thermoplastic polymers, is used for radon detection. \\ High background track numbers in the foils cause big uncertainties for places where the radon concentrations are \\ quite low. Therefore, it is of great importance to lower the background track signal as much as possible, without \\ reducing the sensitivity of the foils. The present study reports track density and sensitivity of Makrofol-DE after \\ thermal annealing. The unexposed foils were heated at temperatures ranging from $110{ }^{\circ} \mathrm{C}$ to $140{ }^{\circ} \mathrm{C}$ for 10 min \\ with the aim of observing changes in the number of background tracks. As a result a reduction in the background \\ track density was observed. In order to observe the change in the sensitivity, pre-heated and unheated foils were \\ exposed to alpha radiation in a radon chamber. At the temperatures of 110,120 , and $130{ }^{\circ} \mathrm{C}$, the track density in \\ the heated and unheated exposed foils is quite similar. An increase was observed in the track density in heated \\ exposed foils at $140{ }^{\circ} \mathrm{C}$.
}

DOI: 10.12693/APhysPolA.125.271

PACS: 81.40.Ef, 77.84.Jd, 29.40.-n, 87.53.Bn

\section{Introduction}

Solid state nuclear track detectors (SSNTDs) have been used in different areas of science such as nuclear physics, particle physics, cosmic ray physics, environmental physics, and archaeology. Thermoplastic is a polymer that is pliable or mouldable above a specific temperature, and returns to a solid state after cooling. Covalent bonds exist within thermoplastics molecular chains and secondary bonds hold groups of polymer chains together to form polymeric materials. Makrofol is a polycarbonate material, is a particular group of thermoplastic polymers, regularly used for radon detection.

Makrofol-DE (white in colour) is a bisphenol-A polycarbonate with a chemical composition of $\mathrm{C}_{16} \mathrm{H}_{14} \mathrm{O}_{3}$ known as a good industrial material with high impact resistance and dimensional stability over a broad temperature range. The presence of the phenyl $\left(\mathrm{C}_{6} \mathrm{H}_{5}\right)$ groups prevents the formation of crystalline structures. In addition, the phenyl rings restrict rotation of the chains around the carbon-carbon bonds. Long chains get entangled with each other and high force is necessary to disentangle them. When the polycarbonate is heated, the chains slide over one another [1].

When ionizing particles like alpha particles and fission fragments pass through a non-conducting material, like crystal, polycarbonate, etc., damaged sites known as latent tracks occur along their paths. Polymers composed of large molecules and the damages form as a result of breaking of the molecular bonds. If an SSNTD is chemically etched after exposure to radon and fission products,

*corresponding author; e-mail: aysegulk@uludag.edu.tr tracks caused by the radiation will enlarge. These tracks can then be counted with an ordinary optical microscope.

The phenomenon of thermal annealing of latent tracks in nuclear tracks detectors is still poorly interpreted due to the lack of information about track formation theory. The annealing is supposed to start with recombination of ions and electrons to form atoms at interstices and later diffusion of atoms towards the damaged zone. The diffusion takes place under stress [2]. One of the advantages of this process is to eliminate the pre-existing background track signal. However, annealing temperature must be carefully applied since overheating causes some structural changes in the detector material and in extreme conditions may even disfigure it [3].

According to our best knowledge, there is no data including close to glass transition temperature and very short-term (10 min) annealing on track of Makrofol-DE. One of the objectives of this study is to decrease the background track density of Makrofol-DE foils without changing the recording sensitivity $\left(V_{\mathrm{t}} / V_{\mathrm{g}}\right)$ by using short-term annealing.

\section{Materials and method}

All the experiments were performed at Gent Laboratory. We used $0.3 \mathrm{~mm}$ thick foils $\left(\mathrm{Makrofol}^{\circledR} \mathrm{DE} 1-4\right.$, commercial product of Bayer AG, Leverkusen, Germany) for the present experiments. Each detector was made of one Makrofol-DE foil with the size of $5 \mathrm{~cm} \times 5 \mathrm{~cm}$ which was cut from $50 \mathrm{~cm} \times 100 \mathrm{~cm}$ sheets.

For the background measurements, Makrofol-DE batches constituting of 20 foils were comprised. The foils were put in a normal drying-oven with making sure that the sensitive sides of them were upside position. The Makrofol foils were heated at 110,130 , and $140^{\circ} \mathrm{C}$ for $10 \mathrm{~min}$. The temperature of the oven was controlled with 
a simple thermometer. Heated and unheated batches were etched to determine the background track numbers.

For the sensitivity measurements, the foils were placed into metal diffusion chambers and these detectors were put into radon chamber. Pre-heated at 110, 120, 130, $140^{\circ} \mathrm{C}$, and unheated detectors were exposed to radon which was supplied by ${ }^{226} \mathrm{Ra}$ source $(5.62 \mu \mathrm{Ci})$. The foils were exposed to radon for three days with a $2.38 \mathrm{l} / \mathrm{min}$ flow rate. The experiments for $140^{\circ} \mathrm{C}$ were repeated twice under similar conditions. All exposed and unexposed foils were stored in air at room temperature before etching.

The foils were pre-etched during $30 \mathrm{~min}$ at $25^{\circ} \mathrm{C}$ in a solution of $95 \%$ ethanol and $6 \mathrm{~N} \mathrm{KOH}$ at a volume ratio of 1 to 5 . After removal of the surface layer (pre-etching), electrochemical etching was then performed in the same conditions as pre-etching applying a high voltage $800 E_{\text {eff }}$ at $2 \mathrm{kHz}$ for $3 \mathrm{~h}$. The detectors were then rinsed with water and dried. The alpha tracks were counted via an optical microscope $(15 \times)$.

\section{Results and discussion}

\subsection{Annealing effect on background track density of Makrofol-DE}

The mean background track densities with \pm 1 standard error obtained from annealed and unannealed foils were demonstrated in Table I. The results indicate that

TABLE I

Background track densities of unannealed and preannealed Makrofol-DE foils for different temperature. Square brackets give number of etched detectors.

\begin{tabular}{c|c|c}
\hline \hline $\begin{array}{c}\text { Annealing } \\
\text { time [min] }\end{array}$ & $\begin{array}{c}\text { Annealing } \\
\text { temperature }\left[{ }^{\circ} \mathrm{C}\right]\end{array}$ & $\begin{array}{c}\text { Track density } \\
{\left[\text { tracks } / \mathrm{cm}^{2}\right]}\end{array}$ \\
\hline- & unannealed & $11.5 \pm 1.44[20]$ \\
10 & 110 & $5.80 \pm 1.06[20]$ \\
& 130 & $5.80 \pm 0.44[20]$ \\
& 140 & $6.05 \pm 0.73[20]$
\end{tabular}

the background track density in annealed Makrofol-DE foils is lower than that of the unannealed Makrofol-DE foils. A similar result was obtained by Meesen et al. [4] for Makrofol-DE foils which were heated at $108^{\circ} \mathrm{C}$ during 24,48 , and $72 \mathrm{~h}$. The repair of a particle track can be achieved by thermal annealing which is governed by a complicated series of molecular process. A track takes place due to the broken molecular chains which produce free radicals. Thermal annealing leads to molecular interdiffusion of whole chains. The rearrangements of molecules are provided by low activation energies in the first stage of annealing. If the sufficient thermal energy is given to plastic, polymer chains interdiffuse and weld together due to the enhanced mobility of molecules of the foils. In the result of this process, strong bonds are established and the repair of damages is achieved. The etch rate $\left(V_{\mathrm{t}} / V_{\mathrm{g}}\right)$ decreases due to the decreasing sensitivity of undamaged regions to etchant. It can be expected that extended defects are resistant to annealing process. Activation energy of annealing of tracks may have only weak dependence on annealing conditions and is a characteristic property of the detector material [5-7].

\subsection{Annealing effect on the track density of Makrofol-DE}

The results, which show the effect of annealing on detector sensitivity for 110,120 , and $130^{\circ} \mathrm{C}$, are presented in Table II. As shown from the mean values with \pm 1 standard error, no significant differences were observed between the pre-annealed and unannealed foils. It was observed that the number of tracks increased for the annealed foils at $140{ }^{\circ} \mathrm{C}$ as shown from Table III.

\section{TABLE II}

Track densities of unannealed and pre-annealed Makrofol-DE foils for different temperature. Square brackets give number of etched detectors.

\begin{tabular}{c|c|c}
\hline \hline $\begin{array}{c}\text { Annealing } \\
\text { time [min] }\end{array}$ & $\begin{array}{c}\text { Annealing } \\
\text { temperature }\left[{ }^{\circ} \mathrm{C}\right]\end{array}$ & $\begin{array}{c}\text { Track density } \\
{\left[\text { tracks } / \mathrm{cm}^{2}\right]}\end{array}$ \\
\hline- & unannealed & $950.9 \pm 26.2[10]$ \\
10 & 110 & $975.7 \pm 35.3[6]$ \\
& 120 & $919.8 \pm 26.1[6]$ \\
& 130 & $951.3 \pm 34.8[6]$
\end{tabular}

TABLE III

Track densities of unannealed and pre-annealed Makrofol-DE foils for $10 \mathrm{~min}$. Square brackets give number of etched detectors.

\begin{tabular}{c|c}
\hline \hline $\begin{array}{c}\text { Track density for } \\
\text { unannealed foils }\end{array}$ & $\begin{array}{c}\text { Track density } \\
\text { for pre-annealed } \\
\text { foils at } 140^{\circ} \mathrm{C}\end{array}$ \\
\hline $910.9 \pm 33.4[10]$ & $1036.4 \pm 39.5[10]$ \\
$739.1 \pm 25.7[10]$ & $837.9 \pm 26.7[10]$
\end{tabular}

In chemical etching, there is the simultaneous action of two processes of chemical dissolution along the particle trajectory at a linear rate $V_{\mathrm{t}}$, referred to as the track etch rate, and a general attack on the etched surface and on the interior of the track at a lower rate $V_{\mathrm{g}}$ referred to as the bulk or general etch rate [8]. The bulk etch rate depends on the material, on the etchant composition, and on the temperature. The track etch rate depends on much greater factors. They can be classified into a few categories: sensitivity of the material, irradiation conditions, post-irradiation conditions, and the etching conditions [9].

Etching efficiency is defined as the fraction of tracks intersecting a given surface that etched on the surface under specified etching conditions, and is given by $\eta=$ $1-V_{\mathrm{g}} / V_{\mathrm{t}}$ [6]. Track fading in polymers is a complicated process, since track etch rate and bulk etch rate are affected by annealing process. Farid [10] observed that there was no change in the bulk etch rate even at $190^{\circ} \mathrm{C}$ for unexposed Makrofol-E detector. Jain et al. [11] investigated etching and annealing kinetics of ${ }^{238} \mathrm{U}$ ion tracks in Makrofol-N and a small reduction in bulk etch rate of Makrofol-N was observed for temperature 
range between 50 and $150^{\circ} \mathrm{C}$. The results of these literatures demonstrate that the bulk etch rate in polymers slightly changes with annealing temperature. Therefore, it was considered that track etch rate of Makrofol-DE foil caused increase in the etching efficiency at $140^{\circ} \mathrm{C}$.

Visible etch track formation processes in polymers whose exposure to alkaline aqueous solutions consists of the penetration of the liquid into the polymer and polymer's glassy to rubbery phase transformation. The passage or penetration of a solution is provided with intrinsic free volume in polymer. The solution moves along the ion tracks, or through undamaged regions towards the tracks. If strong degassing of volatile radiochemical reaction products occurs during radiation damage process, the tracks will appear as regions of excess free volume. If the tracks take place in highly compacted zones with locally reduced free volume, the passage of liquid will become rather hard [12]. In other words, an easy transport along the track core is provided with free volume of polymer, and the etch rate or the sensitivity of detector increases. Consequently, etching efficiency increases with increasing free volume of polymer.

The polymer density $(\rho)$ changes with pressure, temperature, and cooling rate. Specific volume $(V)$ is the reciprocal of density. The volume weight ratio of polymer has a sharp rising above glass transition temperature $\left(T_{\mathrm{g}}\right)$. So, the number of free volume holes, unoccupied area between the polymer chains, is strongly temperature dependent in a given polymer. The glass transition of amorphous polymers occurring at a certain temperature can be defined as the change in polymer chain motions. Below the glass transition temperature, chain motions are quite restricted in short range such as bond rotation, and a bulk polymer is described as a glass. However, polymer remains flexible that is probably provided by side chains. Above this temperature, polymer chain motions are performed in long range because polymer chains gain enough thermal energy to move more freely. So, glassy polymer is softened and becomes rubbery.

The glass transition point of polycarbonate obtained from the inflection point of refractive index was reported in the range between $141^{\circ} \mathrm{C}$ and $149^{\circ} \mathrm{C}$. In addition, the glass transition point obtained by the measurement of expansion coefficient, specific heat, differential thermal analysis, and viscoelasticity, etc. was determined in the range of $130-155^{\circ} \mathrm{C}$ [13]. Besides, the glass transition temperature of polycarbonate has been reported in the range between $140{ }^{\circ} \mathrm{C}$ and $155^{\circ} \mathrm{C}$ in various studies $[14-16]$.

Three fairly distinct annealing ranges can be defined to examine the variation of free volume with temperature in amorphous polymer: truly glassy zone below $T_{\beta}$, aging range between $T_{\beta}$ and $T_{\mathrm{g}}$, and rubbery state above $T_{\mathrm{g}}$. Free volume is very small and almost independent of temperature in the glassy region. In the aging range, the thermal motion of the polymer molecules is not quite zero. In this range, free volume slowly in- creases with temperature, and molecules may experience side chain and/or crank-shaft rotation of the backbone. Above $T_{\mathrm{g}}$, free volume increases rapidly with temperature and the backbone segment starts into Brownian motion, the length of the segment corresponding to the chain entanglement distance [17].

The present experimental results show that a gain in track registration efficiency as high as $13 \%$ can be provided for annealing temperature of about $140^{\circ} \mathrm{C}$. Similar results were obtained by Khan [3] for cellulose nitrate and glass track detectors. Molecular arrangement changes depending on free volume influences on radiation damage process and detection threshold. Since $140{ }^{\circ} \mathrm{C}$ is close to glass transition temperature of polycarbonate, some structural changes such as breakdown of the material, excess rise of free volume take place. There is an inverse relationship between the free volume and molecular weight. The volume weight ratio $\left(\mathrm{cm}^{3} / \mathrm{g}\right)$ of polycarbonate has a sharp rise above $T_{\mathrm{g}}$. Average molecular weight of polycarbonate has a rapid drop under hot or humid conditions and it is also known that the sensitivity $\left(V_{\mathrm{t}} / V_{\mathrm{g}}\right)$ of a polymer increases with a decrease in its molecular weight [6].

\section{Conclusion}

One advantage of the annealing process is that most of the background track signal is eradicated. It can be concluded that the annealing process enhances track registration efficiency of a Makrofol-DE polycarbonate detector at $140^{\circ} \mathrm{C}$. Therefore, in order to decrease the background track density for Makrofol-DE foils without changing the sensitivity, it is sufficient to apply a pre-heating treatment for $10 \mathrm{~min}$ at a temperature in the range of 110 to $130^{\circ} \mathrm{C}$. The facilitated transport is provided by the free volume of polymer and so. If the free volume of polymer increases, an increase in the etch rate takes place around the ion trajectory.

\section{Acknowledgments}

We would like to thank Prof. Dr. Necati Beşirli and Assoc. Prof. Dr. İlker Küçük for their fruitful discussions.

\section{References}

[1] L. Singh, K.S. Samra, J. Macromol. Sci., Part B: Phys. 46, 1041 (2007).

[2] N.K. Sood, T. Singh, A.S. Sandhu, L. Singh, Radiat. Meas. 32, 79 (2000).

[3] H.A. Khan, Nucl. Instrum. Methods 173, 55 (1980).

[4] G. Meesen, A. Poffijn, J. Uyttenhove, J. Buysse, Radiat. Meas. 25, 591 (1995).

[5] M.A. Rana, I.E. Qureshi, S. Manzoor, E.U. Khan, M.I. Shahzad, G. Sher, Nucl. Instrum. Methods Phys. Res. B 179, 249 (2001).

[6] R.L. Fleischer, P.B. Price, R.M. Walker, Nuclear Tracks in Solids: Principles and Applications, University of California Press, Berkeley 1975, p. 1. 
[7] G.S. Sekhon, S. Kumar, C. Kaur, N.K. Verma, S.K. Chakarvarti, Radiat. Meas. 43, 1357 (2008).

[8] N.E. Ipe, P.L. Ziemer, Nucl. Tracks Radiat. Meas. 11, 137 (1986).

[9] P. Apel, Radiat. Meas. 34, 559 (2001).

[10] S.M. Farid, J. Islam. Acad. Sci. 6, 168 (1993).

[11] R.K. Jain, G.S. Randhawa, S.K. Bose, H.S. Virk, Nucl. Instrum. Methods Phys. Res. B 140, 367 (1998).

[12] D. Fink, S. Ghosh, R. Klett, K.K. Dwivedi, Y. Kobayashi, K. Hirata, J. Vacik, V. Hnatowicz, J. Cervena, L.T. Chadderton, Nucl. Instrum. Methods Phys. Res. B 146, 486 (1998).

[13] (www.m-ep.co.jp/en/pdf/product/iupi_nova/ physicality_04.pdf).
[14] K. Neki, P.H. Geil, J. Macromol. Sci., Part B: Phys. 8, 295 (1973).

[15] A.L. Volynskii, T.E. Grokhovskaya, A.I. Kulebyakina, A.V. Bol'shakova, N.F. Bakeev, Polym. Sci., Ser. A 49, 1198 (2007).

[16] T. Wu, S. Lee, W. Chen, Macromolecules 28, 5751 (1995).

[17] Y. Minzi, Ph.D. Thesis, Case Western Reserve University, 1992. 